\title{
Generation Y - The Balance between Lifestyle and Work
}

Doi:10.5901/ajis.2014.v3n3p24

\author{
Agnieszka Stanimir \\ Wroclaw University of Economics \\ Email: agnieszka.stanimir@ue.wroc.pl
}

\begin{abstract}
Generation $Y$ is a group of people born in the 80 s and 90 s of the twentieth century. In each country, determination of the age of persons belonging to this population may differ by several years. Attitudes of people of Generation $Y$ to lifestyle and work, significantly differs from the opinion on this of older generations. The aim of the research was verification if the assessment of variables describing lifestyle and work expectation differs among 16-32 age people in years 2002 and 2012. Analysis of chosen single variables (the most adequate to lifestyle describing) were conducted. Highest differences between study groups were in perception of variable "important to have a good time". Followed correspondence analysis of grouped variables was carried out. Groups of variables were created with those which in a similar way describe lifestyle or work expectations. This procedure made it possible to obtain detailed information about the perception of the variables in the analyzed groups of people. The last analysis was done for all variables. It was a correspondence analysis with use of cluster analysis to indicate corresponding categories of variables. None of the groups of people was characterized by a negating statement for the variables: Important to try new and different things in life, Important to have a good time, Important to be successful and that people recognize achievements, Important to seek fun and things that give pleasure, Important to make own decisions and be free.
\end{abstract}

Keywords: generation Y, lifestyle, work expectations, correspondence analysis, cluster analysis

\section{Introduction}

Genaration $Y$ it is a term used to describe people born between 1980 and 1999, but the age range may differ depending on the country, cultural aspects, and many other factors. For example in USA it may be 1978-1988 (Martin, 2005). For Generation $Y$ functions in the literature many labels, for example "Millenials, Nexters, Generation www, the Digital generation, Generation E, Echo Boomers, N-Gens and the Net Generation" (Tolbize, 2008).

Generation $Y$ in every area of life is using technology and digital media. Quality of life is very important for them as well as life experiences than possessing. They believe that education is a key to success. They are characterized by high opinion of their abilities, belief in their own uniqueness, high expectations and a strong aversion to criticism. They are ready to start their own business with social responsibility. In the other hand they attach much attention to private life, expecting much freedom and flexibility of working time. They want to work, but not a lifelong. "Generation $Y$ sees work as a venue of self-realisation and the boundaries between work and leisure time are becoming blurred in an emerging postmodernist society with a multitude of choices and lifestyles, high transparency in many dimensions and strong market forces, which reduce the influence by the state" (Parment, 2011)

The objective of research concerns on detecting differences in lifestyle and work expectations between young men and women in years 2002 and 2012 in Poland. This article presents the results of research conducted on the Data ESS Round1 and Data ESS Round6. From the questionnaires were taken questions describing lifestyle and work expectations:

1) How happy are you (V1);

2) Important to think new ideas and being creative (V2);

3) Important to be rich, have money and expensive things (V3);

4) Important to show abilities and be admired (V4);

5) Important to try new and different things in life (V5);

6) Important to have a good time (V6);

7) Important to make own decisions and be free (V7);

8) Important to be successful and that people recognize achievements (V8);

9) Important to seek fun and things that give pleasure (V9).

Each respondent chose one of the given response: 
1) V1: Extremely happy, Happy, Neither happy nor unhappy, Unhappy, Extremely unhappy

2) V2, V3, V4, V5, V6, V8, V9: Very much like me, Like me, Somewhat like me, A little like me, Not like me, Not like me at all;

3) V7: Very much like me, Like me, Somewhat like me, A little like me, Not like me.

The analysis was conducted for the data from the years 2002 and 2012. In both periods assumed study group age was 16-32 years. All persons from the indicated age group in 2012 years belonged to the Generation $Y$.

In contrast, people aged 16-32 in 2002 were both the generation $Y$ and generation $X$. Thus, internally, this group could be more diverse because of the lifestyle, than a group of 2012. Gender of respondents was also taken into consideration in analyses.

\section{Analysis of Chosen Questions}

This section presents results of basic statistical analysis performed for selected variables. Analyzed variables in best way describe the lifestyle, and thus attitudes and expectations towards work. The main task was to examine if between men and women aged 16-32 in years 2002 and 2012 are significant differences in lifestyle.

First analyzed question (fig. 1) was: How Happy you are?

Figure 1. Percentage distribution of responses to the question How Happy you are?

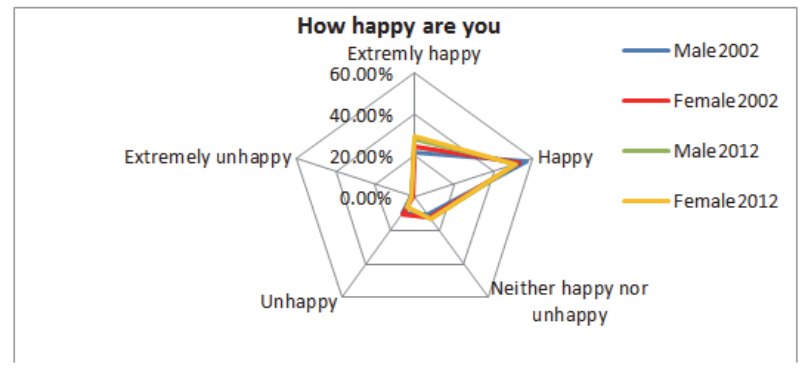

Source: Own elaboration on ESS data.

In both studied periods, the majority of both men and women were happy in their private life. There are no unlikeness between men and women. Their opinions are almost the same in both years. The small difference is visible in answer extremely happy. More men and women in 2012 are extremely happy then in 2002. The question is very general, however, responses indicate that young people were happy in both private and professional life in both periods.

Second analyzed question was: Important to try new and different things in life (fig. 2). It may be assumed that people agreeing with this statement, also in the work will not accept routine and will constantly expect new challenges.

Figure 2. Percentage distribution of responses to the question Important to try new and different things in life?

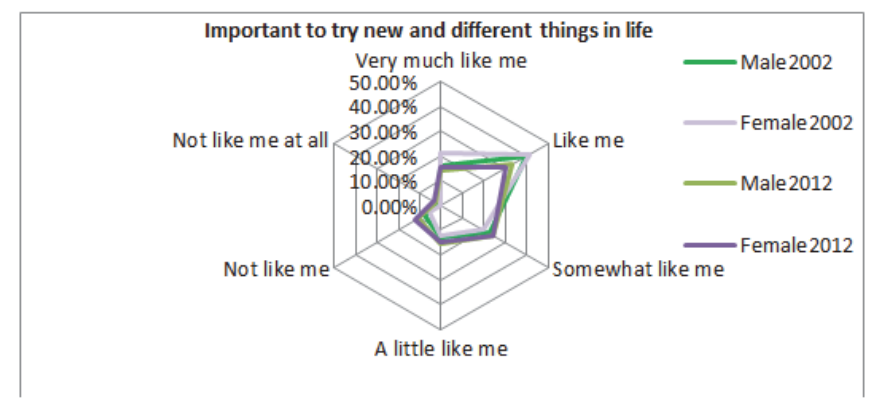

Source: Own elaboration on ESS data. 
Trying new and different things is more important for men and women in 2002 than in 2012. But in both analyzed years trying new and different things is the special feature of young men as well women. Young women in 2002, they learned new things more willing than women of the same age in 2012.

Because the Generation $Y$ is ready to start own business, so they cannot be afraid of making own decisions. Next figure (fig. 3) shows willingness of Generation $Y$ to make decisions.

Figure 3. Percentage distribution of responses to the question Important to make own decisions and be free?

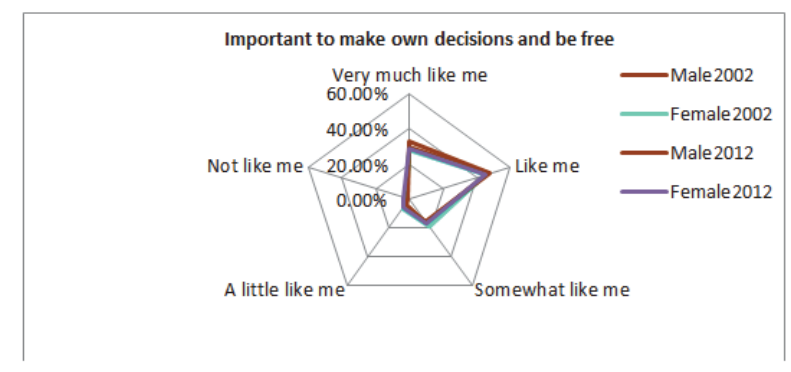

Source: Own elaboration on ESS data.

Over 70\% of young men and women in 2002 and 2012 stated that for them important or very important is to make own decisions and be free. There are not significant differences between women and men in both periods.

Generation $\mathrm{Y}$ is seen as giving priority to good time over work. In fig. 4 percentage distribution of responses to the question if it is important to have a good time?

Figure 4. Percentage distribution of responses to the question Important to have a good time?

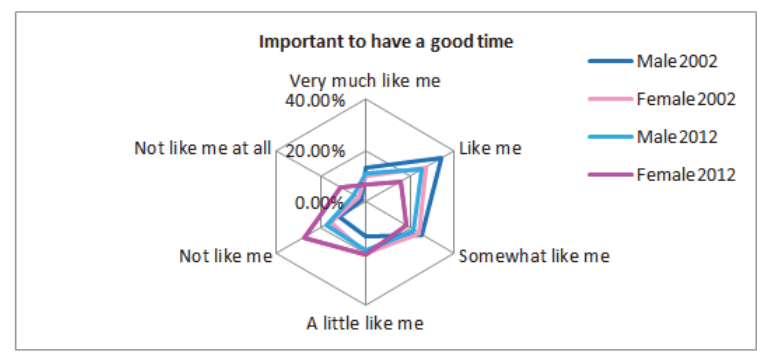

Source: Own elaboration on ESS data.

Opinions of men and women concerning whether having a good time is important for them or not, are different in both years. More women in 2012 than 2002 finds that it is not important for them. The difference between men is not so big, but also more men in 2012 says that having good time is not important. Polish people of Gen $Y$ in the year 2012 were more responsible than those aged 16-32 in 2002.

\section{The Analysis of Lifestyle of Polish Generation Y with Use of CA}

Simultaneous analysis of nine variables identified by many categories, taking into account the years and gender, is not possible using descriptive statistics. Due to the fact that variables were measured at a nominal or ordinal scale, correspondence analysis can be used. 


\subsection{Method of the data analysis}

Blasius and Greenacre (2006) wrote, that "Correspondence Analysis is an exploratory multivariate technique for the graphical and numerical analysis of almost any data matrix with nonnegative entries, but it principally involves tables of frequencies or counts". Most often correspondence analysis is used for describing associations between categories of nominal or ordinal variables. The simultaneous appearances of categories of different variables are shown on low dimensional space. The starting point for this analysis is the contingency table (for two variables) or multidimensional contingency table (for more than two variables, with layers in rows or columns). Coordinates for each category of variables are calculated based on singular value decomposition. If points describing categories are located close together on the plot, it means that categories corresponds to each other. Every axis of the full dimensional space is created based on eigenvalues, which are squares of singular values. The sum of all eigenvalues is called total inertia. The most popular measurement way of quality of fitting in CA is contribution of eigenvalues in total inertia.

In some cases, the perception of position of points on the plot is difficult, particularly when there is a lot of variables, which are described by many categories. In such situations results of correspondence analysis are interpreted with use of cluster analysis.

Cluster analysis it is term for group of method in which the aim is considered on dividing objects into several homogenous groups (Dillon \& Goldstein, 1984). The differences between objects belonging to different groups should be significant. Cluster analysis it is a number of different algorithms and methods for grouping objects due to selected variables. The study use a hierarchical classification by Ward, taking into account the Euclidean distance. Objects for which the classification was made, there were categories of the analyzed in CA variables (V1_1-V9_6, Male2002, Female2002, Male2012, Female2012). Classification variables were coordinates (from low dimensional space) of categories of analyzed variables.

\subsection{Results of the $C A$}

Correspondence analysis was used for the four cases. Firstly variables were divided into three groups. For each groups CA was conducted separately.

In fig. 5 are shown results of CA of assessments of: Important to think new ideas and being creative (V2), Important to try new and different things in life (V5) and Important to make own decisions and be free (V7).

Figure 5. Results of CA of three dependent variables related to making own decision and discovering new things (V2, V5, V7)

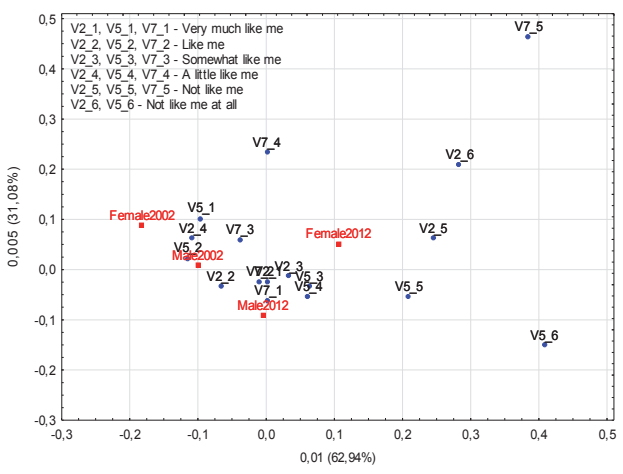

Source: Own elaboration witch Statistica10 on ESS data.

The quality of display of the results in two dimensional space is very high: $62,94 \%+31,08 \%=94,02 \%$. Women in 2002 want to try new things (V5_1), but didn't want to think new ideas (V2_4) or make own decisions (V7_3). Men in 2002 also want to try new thing, but being creative is also characteristic for them. Men in 2012 want to think new ideas or make own decisions, but trying new thing is not so characteristic for them. Female in 2012 are not strongly related with any positive answer of any of this three questions, they are unlikely to make own decisions, try new things or think new ideas. On Fig. 
5 are shown differences in perception of this three variables between women in 2002 and 2012 - more creative were young women in 2012.

In fig. 6 are shown results of CA of respondents perception of: Important to be rich, have money and expensive things (V3); Important to show abilities and be admired (V4); Important to be successful and that people recognize achievements (V8).

Figure 6. Results of CA of three dependent variables related to work expectations (V3, V4, V8)

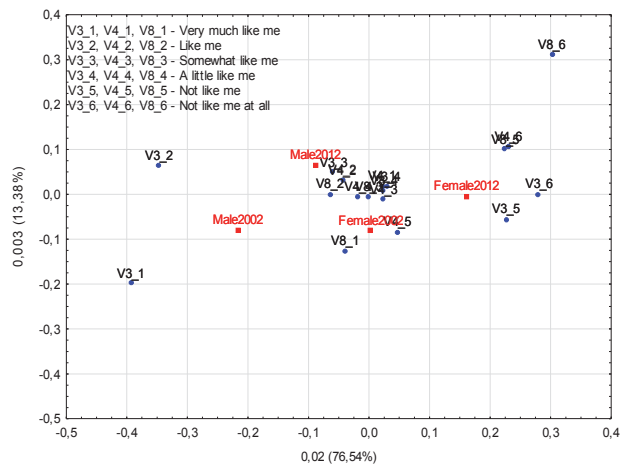

Source: Own elaboration witch Statistica10 on ESS data.

The quality of display of the results in two dimensional space is again very high: $76,54 \%+13,38 \%=89,92 \%$. Women in 2012 says that they didn't want to show abilities, be successful and for them being rich is not important. Quite different situation is by women in 2002 they also didn't want to show abilities but they want to be successful. For men in 2012 important were (but not strongly) to be rich, showing abilities and being admired and being successful. For men in 2002 none of categories of analyzed three variables was characteristic.

The next two variables were assessed jointly: Important to have a good time (V6) and Important to seek fun and things that give pleasure (V9). Results are shown in fig. 7.

Figure 7. Results of CA of two variables related to fun and good time in life (V6, V9)

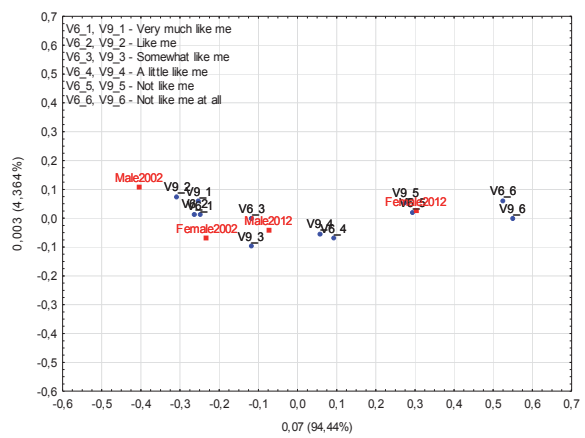

Source: Own elaboration witch Statistica10 on ESS data.

The quality of display of the results in two dimensional space is the highest: $94,44 \%+4,36 \%=98,8 \%)$. For women in 2012 having good time and things that give pleasure wasn't important. Quite different situation is observed for women and men in 2002, they prefer good time and seeking fun.

Last figure (fig. 8) shows results of CA conducted for all variables simultaneously. 
Figure 8. Results of CA of all variables

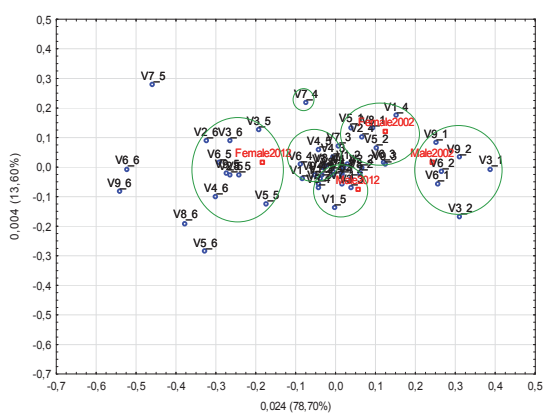

Source: Own elaboration witch Statistica10 on ESS data.

In fig. 8 are marked a group of points which were indicated on the basis of Ward classification. After classification of coordinates in two dimensional space seven clusters were created:

1) Male2002, V3_1, V3_2, V6_1, V6_2, V9_1, V9_2;

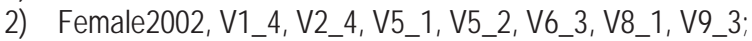

3) Male 2012, V1_5, V2_2, V3_3, V4_2, V7_1, V8_2;

4) V1_1, V1_2, V1_3, V2_1, V2_3, V3_4, V4_1, V4_3, V4_4, V4_5, V5_3, V5_4, V6_4, V7_2, V7_3, V8_3, V8_4, V9_4;

5) Female2012, V2_5, V2_6, V3_5, V3_6, V4_6, V5_5, V6_5, V8_5, V9_5;

6) V5_6, V6_6, V7_5, V8_6, V9_6;

7) V7_4.

In first group are men in 2002 who wanted to be rich, had a good time and were looking for fun.

The second group is created for women in 2002. They wanted to be successful and to try new things, but they were unhappy. Trying new ideas, having good time and seeking fun were them moderately important.

The perception of variables in 2012 by men, is described by the third class. For them very important was making own decision. For this group important were: thinking new ideas, showing abilities and being successful.

In fourth class are categories of variables defining lifestyle and work expectations, which are not characteristic to any group of people. Similarly class number six and seven.

The fifth group consist women (2012), for which, after taking into account all the variables, very characteristic was the attitude of not accepting any mentioned characteristics. However, the analysis separately for each variable allows you to identify the most important characteristics of this group.

\section{Conclusions}

There are differences between attitudes of men and women taking into account all variables (V1-V9). Correspondence analysis of all variables simultaneously shows attitudes in all analyzed problem. In-depth conclusions can be drawn after statistical analysis separately for each variable or by correspondence analysis of selected groups of variables.

\section{Acknowledgements}

This study was done as a part of the project "Non-metric multivariate data analysis as a tool for study of adults situation in the context of demographic changes" financed by Narodowe Centrum Nauki (National Science Centre) in Poland. Project number: 2012/05/B/HS4/02499.

The data on individuals were retrieved from Data, ESS Round 1: European Social Survey Round 1. (2002). Data file edition 6.3. Norwegian Social Science Data Services, Norway - Data Archive and distributor of ESS data and Data, ESS Round 6: European Social Survey Round 1. (2002). Data file edition 2.0. Norwegian Social Science Data Services, Norway - Data Archive and distributor of ESS data. 


\section{References}

Blasius, J., \& Greenacre, M. (2006). Correspondence Analysis and Related Methods in Practice. W M. Greenacre, \& J. Blasius, Multiple Correspondence Analysis and Related Methods (strony 3-40). New York: Chapman \& Hall/CRC, Tylor \& Francis Group.

Data, ESS Round 1: European Social Survey Round 1. (2002). Data file edition 6.3. Norwegian Social Science Data Services, Norway Data Archive and distributor of ESS data.

Data, ESS Round 6: European Social Survey Round 6. (2012). Data file edition 2.0. Norwegian Social Science Data Services, Norway Data Archive and distributor of ESS data.

Dillon, W. R., \& Goldstein, M. (1984). Multivariate Analysis. Methods and Applications. Singapore: Hohn Wiley \& Sons.

Martin, C. A. (2005, 37). From high maintenance to high productivity. What managers need to know about Generation Y. INDUSTRIAL AND COMMERCIAL TRAINING, strony 39-44.

Parment, A. (2011). Generation Y in Consumer and Labour Markets (Routledge Interpretive Marketing Research). Routledge.

Tolbize, A. (2008). Generational differences in the workplace. Minnesota: Research and Training Center on Community Living, University of Minnesota. 